\title{
Participant observation at events: theory, practice, and potential
}

\section{Introduction}

The paper reviews the method of participant observation (Spradley, 1980) as part of the broader qualitative research paradigm (Denzin and Lincoln, 2000), and discusses its strengths and weaknesses as a research method. A review of its application in published research demonstrates its utility in many research settings, including education, entertainment, travel, and retail. To date, its use in empirical research regarding event studies has been limited, yet it holds great promise for uncovering new understandings of visitor motivation, satisfaction, and social behaviour. The paper offers a case study example of its practical application at an arts event in Australia, where for many years festival managers have used structured participant observational methods to gather data and market intelligence with respect to their audience's needs and expectations.

\section{Theoretical review}

Participant observation is a part of the broader qualitative research paradigm (Denzin and Lincoln, 2000), where the researcher serves as the primary instrument for observing and collecting data (Creswell, 2003). Qualitative researchers operate under six assumptions (Merriam, 1988, p.19-20):

1. The focus of the research is on the process rather than outcomes,

2. The research has an interest in meaning - how people make sense of their lives, or what is happening around them,

3. The researcher is the primary instrument for data collection and analysis and the data are mediated through this instrument,

4. Research involves fieldwork, 
5. Research is descriptive, seeking meaning or understanding,

6. Research is inductive, building concepts, theory, and abstractions from the details.

As a method of qualitative research, participant observation is recognised as appropriate for gathering data on interactions and relationships through the recording of behaviour, conversation, and experience in situ (Van Maanen, 1995). Participant observation is suited to many aspects of event research, where a need or desire exists to explore aspects of audience behaviour, but it is especially useful where on-site surveying techniques are inappropriate. While quantitative studies using survey data have proven effective for establishing the economic impact of events, the demographic profile of audiences, or the basis of audience motivation, many more aspects of audience behaviour require exploration and understanding. For example, quantitative surveys can show that a film festival attracts a large ratio of return visitors each year, but they do not explain how or why that return occurs.

Participant observation can assist researchers in better understanding the relationships between audience groups, as well as those between the activities of the event and the audience. "The methodology of participant observation is exceptional for studying processes, relationships among people and events, the organization of people and events, continuities over time, and patterns, as well as the immediate sociocultural contexts in which human existence unfolds" (Jorgensen, 1989, p. 12). While this comment does not refer specifically to special events and festivals, the purposes for conducting participant observation clearly apply to the context of events and their audiences.

\section{The research process}

Participant observation takes place as a qualitative research cycle that begins with the researcher's selection of a project in a social setting, from which the researcher proceeds by asking ethnographic questions, collecting data, making a record, analysing data, and writing a 
manuscript (Spradley, 1980). The cycle then begins again, as the results often initiate new research questions in the same or different social scene.

The process of participant observation requires the researcher to become involved as a participant in a social setting and make descriptive observations of him/herself, of others, and of the setting. The extent to which the researcher becomes involved needs to be made explicit. The degree of involvement both with people and in the activities will vary considerably between researchers and between events, and the researcher must decide on the extent of participation. Prior research suggests five types of participation on a continuum of involvement: (1) complete, (2) active, (3) moderate, (4) passive, and (5) non-participation (Spradley, 1980). The scope and scale of events make all of these positions possible, as some situations offer no opportunities for involvement, whereas others can allow for high involvement. As examples, ethnographic research as a competitor in a triathlon would offer “complete" participant involvement, whereas attending a music festival as a spectator offers "moderate" involvement - to be both an "insider" (participating in the process of purchasing tickets, sitting in the spectator area) as well as an "outsider" who is observing spectator behaviour.

A thorough understanding of participant observation in event settings requires researchers to consider their position and role in the research. By attending the event even as a passive spectator, the researcher becomes a participant in the event, taking part in the social setting. Once in the event setting, the researcher can make observations by using field notes, photographic and video images, artefacts, merchandise, programs, websites, and any other sources that help to document the event. "Participant observers commonly gather data through casual conversations, in-depth, informal, and unstructured interviews, as well as formally structured interviews and questionnaires" (Jorgensen, 1989, p. 22). Images and video are especially useful to the researcher of events where things are happening en masse, 
in large crowds and at a fast pace. These images can then be reviewed after the event in the "blow up and show up effect" (Crawford and Turton, 1991, p. 12). These observations form an ethnographic record, which along with descriptive, focused, and selective observations becomes the data the researcher uses for analysis.

The analysis of the observational data is a critical step, which may be taken in various ways in a search for patterns and themes (Creswell, 2003). Data analysis comprises a detailed sequential process that begins with an overview of the cultural scene and a search for cultural domains - categories of meaning that often contain subcategories (Spradley, 1980). Participants at an arts event, for example, may constitute a cultural domain that comprises subdomains of musicians, circus acts, buskers, performing artists, and dancers. Through the analysis, the researcher is discovering the pattern and organisation of human behaviour.

Domain analysis involves establishing the domains through semantic relationships (e.g., $\mathrm{X}$ is used for $\mathrm{Y}$ - a small stage is used for buskers). A taxonomic analysis follows, coupled with obtaining more focused observations (Spradley, 1980). Finally a componential analysis searches for the attributes associated with cultural categories by finding contrasts between cultural categories and subdomains (e.g., buskers interact with spectators, but dancers do not). Further analysis can result in cultural themes that may assist in reporting the results.

\section{Strengths and weaknesses of the method}

In assessing the suitability of the observational research method to the study of festivals and events, investigators should be aware of its strengths and weaknesses. The main strength of the method is that it doesn't interrupt the event experience for spectators or participants. Researchers can make observations of people while they are dancing, running, sailing, or engaging in any other activity, and can be used in situ, where decisions are made and behaviours are undertaken. This aspect has proven invaluable for research in retail, where 
researchers are interested in the decisions consumers make in the stores or in the shopping mall (Morrison, 2002).

Secondly, the research can uncover, explore, and describe new behaviours. Because theory or hypotheses are not established $a$ priori, the researcher is open to all new explanations of behaviour. According to Morrison, "A major advantage of participant observation is that you get fresh impressions, right as things happening. You can see how the experience evolves, how the impressions change, how people navigate a situation" (Morrison, 2002, p. 31).

Thirdly, participant observation can provide deeper understanding of participants' subculture through analysis of their phrases and semantics, leading to discovery of the reasons situations are occurring. This aspect was particularly useful in a study of the subculture of motorcycle enthusiasts, which led to strategies to improve public order at the Australian Motorcycle Grand Prix (Veno and Veno, 1992), as well as in other research aimed at better understanding the social behaviour of sports fans (Fairley, 2003; Fairley and Tyler, 2012).

While the participant observation method has clear advantages, it also has weaknesses. The method is not without critics, particularly in terms of reliability and validity (McCall and Simmons, 1969; LeCompte and Goetz, 1982). Additionally, as with other forms of qualitative research, the results cannot be generalized to other events or to other years of the same event, because the results are specific to the cultural setting in which they were formed. However, this aspect should be considered in perspective alongside survey-based research into the demographics or motivations of event visitors, where results are often equally as event-specific. A study of four events in New Zealand found that "[e]vent-goers do not appear to constitute a single homogeneous market; rather, different events appear to attract different audiences" (Nicholson and Pearce, 2000, p. 236). A review of other 
motivational studies concurs with the finding (Getz, 2010). Since results of event studies are very often event-specific, more information could be captured about the precise context of the event, and the social setting, to deepen the understanding of the phenomena.

A further weakness is that where the researcher is the data collection instrument, the experiences and bias of that researcher influence the results. This assumption underpins most qualitative research, and needs to be addressed by the researcher in the reporting. To enhance the external reliability of their data, investigators need to recognise and alleviate issues in researcher status, informant choices, social situations and conditions, analytic constructs and premises, and methods of data collection and analysis (LeCompte and Goetz, 1982).

Standard techniques to ensure the validity of qualitative research include having other qualified researchers independently code the material, undertake peer reviews, or facilitate triangulation, thus providing corroborating evidence through multiple sources (Creswell and Miller, 2000). Using a trained team of researchers to supply multiple accounts of the event can also assist in triangulation. Participant observation may be conducted by a single researcher or by a team of trained researchers: "Team strategies offer distinctive advantages, such as the possibility of performing different participant and observer roles simultaneously as well as exploiting various talents and identities (such as gender) of the researchers" (Jorgensen, 1989, p. 22).

Many events have a large team of volunteers from which small teams of researchers can be drawn, and where the different ages of volunteers can be used to actively observe and interact with different age groups at an event. A team of volunteers can also operate in different areas of the venue at the same time. However, observers must be trained effectively thoroughly in a thorough briefing session before they enter the social setting, including discussing the anticipated problems and objectives of the research and planning a collaborative approach: According to Delamont, "The biggest problem novices find when 
preparing for ethnographic fieldwork is that the methods books are not explicit enough about what to observe, how to observe and what to write down" (Delamont, 2007, p. 212).

One caveat applies to the selection of the participant observation method. Not all researchers are suited to participant observation, as it requires well developed interpersonal skills and both sensitivity and creativity (Jorgensen, 1989), as well as a willingness to engage in the cyclical process (Spradley, 1980), which takes a less straightforward approach to research than the linear scientific method.

\section{Applications of participant observation research}

Observation through participation has been used extensively as a research method in situations where behaviours are complex, difficult, or embarrassing for participants to recall or describe. In other situations it has been used to simply understand new social phenomena or explore human behaviour (DeWalt and DeWalt, 2002). It is widely used in education, where researchers observe teaching in classrooms (Woods, 1986), as well as in retail shops (Sinha and Uniyal, 2005; Morrison, 2002), with soccer hooliganism in the UK (Giulianotti, 1995), and in health care (Mays and Pope, 1995). In disciplines that intersect with event studies, participant observation has been used to explore decision making in tourism (Blichfeldt, 2008), consumer satisfaction with travel (Bowen, 2002), and volunteerism (Grimm and Needham, 2012). In the arts it has described why people go to the theatre (Walmsley, 2011), and in sport it has deepened knowledge of why some fans travel to follow professional sport teams (Green, 2001; Fairley, 2003) and it has collected their impressions of attending a cinema to view baseball games (Fairley and Tyler, 2012).

Despite its effectiveness as a research method for exploring human behaviour in many social settings, participant observation has been limited with respect to event and festival studies. Kyle and Chick (2002) investigated the social reasons for campers' annual return to participate in a fair in the US, and Mackellar (2009) observed the differences and behaviours 
of fans at the Elvis Presley Festival in Australia. Gilmore and Van Proyen (2005) have described various experiences of the Burning Man Festival (US), and Liburd and Derkzen (2009) explored a Danish festival's effect on quality of life. Nevertheless, while Holloway et al. (2010) provide a strong rationale for the use of ethnographic research in event settings, its value as a research method has not fully been explored.

Prominent event studies researcher Donald Getz has been critical of the reliance on quantitative studies of festival visitor motivation, stating;

Almost entirely, scholars listed in this bibliography have adopted the positivistic, quantitative paradigm favoured by consumer behaviour studies, even though this approach fails to consider fundamental social and cultural antecedents. It also gravely over-simplifies motivation (and completely ignores need) by commodifying festivals alongside other entertainment products (Getz, 2010, p. 10).

Getz also indicates that qualitative methods may have far more potential to discover aspects of leisure behaviour, but unlimited opportunities also exist to look at the behaviour of participants, spectators, volunteers, media, and host communities. Perhaps the greatest potential for participant observation in event settings lies in examining the social dynamics of audiences and the reasons for their behaviour. Work by sports tourism researchers (Fairley and Tyler, 2012; Green and Chalip, 1998; Shipway and Jones, 2008) offers some insight into the potential in this area and demonstrates the possibilities of researching the experiences of audience groups before, during, and after the event. Alternatively, the method offers promise for exploring the affective domain to discover more about the emotional impact of events on audiences and their engagement, as evidenced in relation to Celtic festivals and the transcendent experiences participants found there (Matheson, 2008). 


\section{The event environment}

Events are busy and dynamic places, where situations and audience behaviours and moods can change quickly. Studies of crowd behaviour at music festivals, for example (Earl, 2008), have shown these events to be unique social settings where crowds are emotionally charged and highly unpredictable. Participant observation offers an unobtrusive way to collect data through structured means of observation, recording, and analysis - important activities in the context of event environments, where the use of surveys can interrupt the flow of the event experience for consumers or be precluded by the staging and operations of the event.

While few empirical studies of participant observation exist, evidence is available that event managers have been using it for some time to record the experiences of audiences and analyse them for future event development. The following case study was developed using semi-structured interviews with the event managers and other sources of event documentation, such as images, websites, and outcome reports (Yin, 1994). The case demonstrates the potential participant observation offers in one event situation.

\section{Case study}

Managers of the Swell Sculpture Festival in Currumbin, Queensland, actively use participant observation as part of their audience development strategy to understand and manage audience expectations. The festival is an open-air event held on the esplanade along a 1-km stretch of beach in Currumbin, on the Gold Coast, Australia. Over 50 sculptures stand in the open space, delicately placed in the parklands and sand dunes on the beachfront without protective barriers or fences. The free exhibition attracts around 60,000 visitors over 10 days and can be accessed 24 hours a day- with a selection of sculptures lit up in the evenings. Visitors can experience the sculptures as well as engage in artist talks, a public art forum, master classes, and children's workshops. 
The public location provides challenges to the management of the event in terms of balancing the expectations and safety of the visitors and protecting the valuable sculptures from accidental or intentional damage. Over the past 10 years, the managers have explored various ways of collecting useful information on the behaviours and expectations of visitors. These approaches include some visitor surveys, but primarily comprise structured observation - watching, listening, and recording visitor experiences at the event and then reporting these observations to management. Management selects volunteers and instructs them on when, how, and where to make observations, and provides them with materials such as note pads and cameras to record their observations. These volunteers are thus "active participants", observing and engaging in the same activities as spectators at the event as well as getting an insider's view of the management of the event.

From volunteers' reports, the event managers can in some cases make immediate adjustments to security issues or can compile the field notes for later analysis. The event managers also find time to make their own observations of visitors interacting with the sculptures and to listen to the conversations at the event, taking many images of the interactions between the audience and the sculptures.

Over the 10 days of the event, the managers analyse the multiple sources of data, looking for patterns and contrasts and developing themes for further action or documentation. Analysis is mostly done through notes on paper and through conversations with the staff and volunteers at the event (member checking). The results contribute to the final outcomes report, which is distributed to sponsors and funding bodies, but importantly contributes to the on-going development of management policies.

These data have been vital to developing policies relating to the curation of the sculptures. As the Festival Director explains, 
[W]e have found that visitors expect to be able to interact with the pieces, and to get close to them, even to touch them, and let their children crawl on them. We have to balance these expectations with the protection of the works. We can find out more about what they would like, and what they are really enjoying, by watching them and listening to them, than by conducting a survey.

Interestingly, observing the interactions of the audience led to the discovery that other members of the audience will intervene if people engage in destructive or negative behaviours, telling those who are out of order that the materials are fragile or pointing out small signs that ask not to touch certain pieces. The Festival Director noted, "We don't want to put up fences, or barriers, or even large imposing signs telling people what not to do, but we have observed how the local community, and other visitors, have taken ownership over the works and are quite protective of them".

Over the years since the event's inception, the managers have also observed the prevalence of travelling groups of between four and five people, and the social roles group members take on within the group: the planner, who sets about planning how the group will get from one part of the venue to the next; the interpreter, who buys the program and reads the details of the sculpture aloud; the caterer, who organises where and when to get coffee and food; the reviewer, who listens to the details and then makes an individual critique. These social groups of families and friends are an important part of the audience and can be catered to. The Festival Director explained, "Spaces are needed for these social groups to just sit and consider their experience and the artwork-we don't want people to feel rushed through the venue".

The case study illustrates the capacity of participant observational techniques to enlarge understanding of visitors' behaviours and their interaction with the artworks. However, the event managers noted that a great deal of other information also comes from 
these techniques, including that relating to the placement of food stands, areas of traffic and parking congestion, and disruption of pedestrian flows. The festival managers value the structured observations of volunteers and have created a process by which the volunteers can feed that information to the managers accurately. From this information, they can analyse results, formulate themes for audience development, and prioritise changes to the event in future years.

\section{Discussion and implications}

As the case study demonstrates, participant observation is a research method by which event managers can collect information to inform the development of event management strategies related to audience expectations and public risk and safety. Additionally, the paper presents the potential for participant observation as a tool for other management strategies. By unobtrusively observing the social interactions of audiences, both event managers and researchers can gain new insights into audience behaviour and discover how audiences create meaning from their experiences during an event. In this case, the desire to engage with the art and to freely access it is integral to the meaning of the festival-goers' experience, demonstrating that participant observation provides meaningful, event-specific data. While many quantitative studies of festival visitors identify aspects such as "social reasons" as a motivation to attend events, participant observation allows exploration of the dynamics of social group interaction and the specific roles of the groups. This information can inform the development of management strategies to facilitate the audience members' social needs, or to simply understand their event experience.

\section{Conclusion}

A review of the methods of participant observation in event settings suggests great potential for future research to uncover new insights into audience behaviour and expectations. The ability to unobtrusively observe crowd behaviour and to systematically analyse observational 
data offers potential for researchers to adopt a new approach to event research. While the technique has acknowledged limitations, many of these can be managed by the researcher to maximise the credibility of the research. 


\section{References}

Blichfeldt B. (2008), What to do on Our Holiday: The Case of in Situ Decision-Making. Anatolia, Vol. 19: 287-305.

Bowen J. (2002), Research through Participant Observation in Tourism: A Creative Solution to the Measurement of Consumer Satisfaction/Dissatisfaction (CS/D) among Tourists, Journal of Tourism Research, Vol. 41: 279-294.

Crawford PI and Turton D. (1991), Film As Ethnography, Manchester: University Press.

Creswell JW. (2003) Research design: Qualitative, quantitative and mixed method approaches, Thousand Oaks; California: Sage Publications.

Creswell J.W and Miller DL. (2000), Determining Validity in Qualitative Inquiry. Theory Into Practice, Vol. 39: 124-130.

Delamont S. (2007), Ethnography and participant observation. In: Seale C, Gobo, G., Gubrium, J., Luerman, D. (Eds) Qualitative Research Practice. LA: Sage, 205-217.

Denzin N and Lincoln Y. (2000), Handbook of Qualitative Research, Thousand Oaks. California: Sage Publications. .

DeWalt K and DeWalt B. (2002), Participant Observation : a guide for fieldworkers, Walnut Creek, CA: AltaMira Press.

Earl C. (2008), Crowds at Outdoor Music Festivals: An Examination of Crowd Psychology and Its Implications for the Environmental Health Practitioner. Environmental Health, Vol. 8: 34-43.

Fairley S. (2003), In Search of Relived Social Experience: Group-Based Nostalgia Sport Tourism. Journal of Sport Management, Vol. 17: 284. 
Fairley S and Tyler BD. (2012), Bringing Baseball to the Big Screen: Building Sense of Community Outside of the Ballpark. Journal of Sport Management, Vol. 26: 258-270.

Getz D. (2010), The nature and scope of festival studies. International Journal of Event Management Research, Vol. 5: 46.

Gilmore L and Van Proyen M. (2005), AfterBurn : reflections on Burning Man, Albuquerque: University of New Mexico Press.

Giulianotti R. (1995), Participant observation and research into football hooliganism: reflections on the problems of entrée and everyday risks. Sociology of Sport Journal, Vol. 12: $1-20$.

Green BC. (2001), Leveraging Subculture and Identity to Promote Sport Events. Sport Management Review, Vol. 4: 1-19.

Green B.C. and Chalip L. (1998), Sport tourism as the celebration of subculture. Annals of Tourism Research, Vol. 25: 275-291.

Grimm K.E. and Needham MD. (2012), Moving Beyond the "I" in Motivation: Attributes and Perceptions of Conservation Volunteer Tourists. Journal of Travel Research, Vol. 51: 488-501.

Holloway I, Brown L. and Shipway R. (2010), Meaning not measurement: Using ethnography to bring a deeper understanding to the participant experience of festivals and events. International Journal of Event and Festival Management, Vol. 1: 74-85.

Jorgensen D. (1989), Participant Observation : a methodology for human studies, Newbury Park, Calif.: Sage Publications. 
Kyle G and Chick G. (2002), The Social Nature of Leisure Involvement. Journal of Leisure Research, Vol. 34: 22.

LeCompte M and Goetz J. (1982), Problems of Reliability and Validity in Ethnographic Research. Review of Educational Research, Vol. 52: 31-60.

Liburd JJ and Derkzen PHM. (2009), Emic perspectives on quality of life: the case of the Danish Wadden Sea Festival. Tourism and Hospitality Research, Vol. 9: 14.

Mackellar J. (2009), Dabblers, fans and fanatics: Exploring behavioural segmentation at a special-interest event. Journal of Vacation Marketing, Vol. 15: 5-24.

Matheson C. (2008), Music, Emotion and Authenticity: A Study of Celtic Music Festival Consumers. Journal of Tourism and Cultural Change Journal of Tourism and Cultural Change, Vol. 6: 57-74.

Mays N and Pope C. (1995), Qualitative Research: Observational methods in health care settings. British Medical Journal, Vol. 311: 2.

McCall G and Simmons J. (1969), Issues in participant observation; a text and reader, Reading, Mass.: Addison-Wesley Pub. Co.

Merriam SB. (1988), Case study research in education: A qualitative approach. San Francisco: Jossey-Bass.

Merriam SB. (2009), Qualitative research : a guide to design and implementation, San Francisco: Jossey-Bass.

Morrison MA. (2002), Using qualitative research in advertising : strategies, techniques, and applications, Thousand Oaks, Calif.: Sage. 
Nicholson R and Pearce D. (2000), Who goes to events: A comparative analysis of the profile characteristics of visitors to four South Island events in New Zealand. Journal of Vacation Marketing, Vol. 6: 236-253.

Shipway R and Jones I. (2008), The Great Suburban Everest: An 'Insiders' Perspective on Experiences at the 2007 Flora London Marathon. Journal of Sport \&Tourism, Vol. 13: 61-77.

Sinha P and Uniyal D. (2005), Using observational research for behavioural segmentation of shoppers. Journal of Retailing and Consumer Services, Vol. 12: 35-48.

Spradley J. (1980), Participant Observation, Fort Worth.

Van Maanen JE. (1995), Representation in Ethnography, Newbury Park, CA: Sage Publications.

Veno A and Veno E. (1992), Managing public order at the Australian motorcycle grand prix. American Journal of Community Psychology, Vol. 20: 287-308.

Walmsley B. (2011), Why people go to the theatre: A qualitative study of audience motivation. Journal of Customer Behaviour, Vol. 10: 335-351.

Woods P. (1986), Inside schools, ethnography in educational research. Available at: http://site.ebrary.com/id/10096321.

Yin R. (1994), Case study research: design and methods, Thousand Oaks: Sage Publications. 